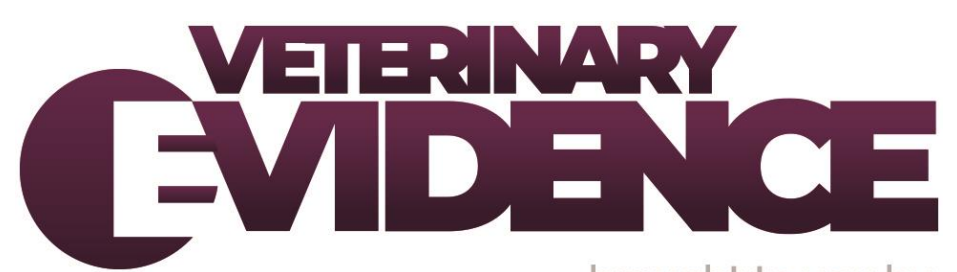

\title{
Clinical governance and continuous Quality Improvement in the veterinary profession: A mixed-method study
}

Tom Ling MA PhD ${ }^{1}$

Ashley Doorly ${ }^{2 *}$

Chris Gush BSc MSc ${ }^{2}$

Lucy Hocking BSC MSc ${ }^{1}$

1 RAND Europe, Westbrook Centre/Milton Rd, Cambridge, CB4 1YG
2 RCVS Knowledge, Belgravia House, 62-64 Horseferry Road, London, SW1P 2AF
${ }^{*}$ Corresponding Author (ashley@rcvsknowledge.org)

ISSN: 2396-9776

Published: 12 May 2021

in: The Veterinary Evidence journal Vol 6, Issue 2

DOI: 10.18849/VE.V6I2.383

Reviewed by: Jo Ireland (BVMS Cert AVP(EM) MRCVS PhD) and Tim Mair (BVSC PhD DEIM DESTS DipECEIM AssocECVDI MRCVS) 
$96 \%$ of the veterinary profession agrees that Quality Improvement (QI) improves veterinary care. While clinical governance is an RCVS professional requirement, over the last year only $60 \%$ spent up to 3 days on the Quality Improvement activities which allow clinical governance to take place. $11 \%$ spent no time on it at all. A lack of time, know-how and organisational support were among the barriers preventing its adoption in practice.

Rather than being an individual reaction to a problem, Quality Improvement is a formal approach to embedding a set of recognised practices, including clinical audit, significant event audit, guidelines and protocols, benchmarking and checklists. This framework should be applied within a just culture where errors are redefined as learning opportunities, and precedence is given to communication, team-work and teammorale, patient safety, and distributed leadership.

Addressing this gap will require evolution - rather than a revolution. Persistent packages, given enough time and addressing the whole flow of the patient journey, trump one-off 'heroic' and narrowly-focused interventions. Creating a rhythm of learning alongside stability of practice allows lessons to be absorbed and improvements routinised. Doing good things well is better than doing perfect things sporadically and helps address the widespread concern that there is insufficient time for QI by making the time commitment more predictable and manageable.

The research provides a robust, evidence-based, roadmap for the entire sector including professional organisations, educators, those in management positions and care providers.

\section{INTRODUCTION}

Quality Improvement (QI) involves a set of inter-related steps: taking a systematic approach to understanding a problem, measuring its scale, identifying and then testing a potential improvement, reviewing the results and then starting again. Within this broad definition there are many varied practices. Why might any group of people who work together engage with Quality Improvement when it involves taking time out of primary tasks? Early examples from the car industry, for example, highlight the importance of senior management buying into the approach and subsequently securing buy-in from staff in a top-down way. In human healthcare, the role of senior leadership in delivering improvement is different to the car industry, for example, (where many improvement processes were first formalised); in human healthcare often senior figures learned about improvement from external organisations such as the Institute for Health Improvement, and returned committed, and seeking change in their host organisation. This formalised approach to improving human healthcare quality arose around the turn of the $21^{\text {st }}$ century and was self-consciously a new way of thinking about quality. Quality came to be defined as involving six domains (Institute of Medicine (US) Committee on Quality of Health Care in America, 2001):

- Safety

- Patient Centeredness

- Timeliness

- Effectiveness

- Efficiency

- Equity 
Alongside this definition of quality, there developed a self-professed 'science of improvement' and, reflecting this, a set of practices that became collectively known as Quality Improvement (QI) with upper case (indicating it is a distinct entity). In this article we use QI to describe this distinctive approach while we will also refer more generally to wider efforts to improve quality as, simply, 'improving quality'. Thus, a whole system approach to embedding recognised techniques ${ }^{1}$ would count as QI while singular actions such as attending Continuing Professional Development (CPD), holding a clinical governance meeting, or purchasing new equipment could be 'improving quality'.

It would be wrong to regard QI as either uniformly successful or universally applied in human healthcare, but it involves a set of practices recognised to be different from one-off improvement efforts. Rather than being an individual reaction to a problem it is better thought of as a framework within which improvement can be systematically addressed. Much of this thinking developed first in the United States and was associated with two studies completed at the turn of the century: To Err is Human: Building a Safer Health System (Institute of Medicine (US) Committee on Quality of Health Care in America, 2000) and Crossing the Quality Chasm: A New Health System for the $21^{\text {st }}$ Century (Institute of Medicine (US) Committee on Quality of Health Care in America, 2001). This new framework was multi-faceted but included a movement away from a focus on checking the decisions of individual clinicians and punishing errors, and instead proposed building systems within which teams could work together, peers could support one another, and errors were redefined as learning opportunities (Agency for Healthcare Research and Quality, 2013; The Health Foundation, n.d.).

Subsequently, people in parts of the veterinary profession in the UK actively engaged with the idea that lessons might be learned and adapted from the improvement framework being developed in human healthcare (as well as QI in other industries beyond healthcare). In particular, in 2017 RCVS Knowledge identified a group of practitioners that they considered to be 'early adopters' and invited them to form a Quality Improvement Advisory Board (QIAB). RCVS Knowledge sought to become not only a 'hub' for improvers to learn and connect, but also a driver of change focused on five areas for action (RCVS Knowledge, 2017):

1. Clinical audit

2. Benchmarking

3. Significant event audit

4. Guidelines

5. Checklists

This approach includes a recognition of the importance of 'top-down' approaches to establishing and extending clinical audit and so forth, but it was also sensitive to the importance of professionals 'selfidentifying' as improvers and engaging with it not only in response to demands from above but also as part of a shared identity of veterinary surgeons and veterinary nurses having 'two jobs'; not only delivering care but also improving the care delivered.

It was in this context that RAND Europe ${ }^{2}$ was commissioned by RCVS Knowledge to conduct primary research and to work collaboratively with RCVS Knowledge to generate insights and learning regarding the current state of $\mathrm{Ql}$ in the veterinary profession, their appetite for change, and to make recommendations for further progress. This article reports on that research; what was found, and what was recommended, and the future actions for those organisations and people who are involved in animal healthcare.

\footnotetext{
${ }^{1}$ This would include identifying areas for improvement through significant event auditing, clinical auditing and benchmarking. Embedding change through checklists, guidelines and protocols. Measuring the success of that change through clinical audits and benchmarking. These steps should be repeated continuously.

A useful directory of tools for Quality Improvement can be found here: https://www.hqip.org.uk/wp-content/uploads/2021/01/FinalQuality-Improvement-QI-Tools-09-12-20.pdf

2 https://www.rand.org/randeurope.html
} 
Before discussing the findings from the veterinary sector, it is important to briefly reflect on the transferability of lessons from QI in human healthcare. It would be strange if those wishing to support QI in animal healthcare were not interested in learning lessons from human healthcare where, as we have seen, there has been a longer history. However, if lessons are to be learned, it is necessary to also understand the peculiarities that would be relevant for applying lessons to an animal health setting. Some implications from human healthcare include:

1. For QI to be successfully embedded, the veterinary sector will need to first understand the quality of care that is already being provided. To do this, it must build data collection systems on a national scale capable of measuring the extent of existing problems and measuring the effects of improvement. This is key to entrenching improvement practice. However, despite recent improvements (for example, in the RCVS Practice Standards Scheme (PSS) for hospital accreditation, and in the Supporting Guidance to the RCVS Code of Professional Conduct for Veterinary Surgeons and Veterinary Nurses ${ }^{3}$, where there is an emphasis on the importance of collecting data via audits) data collection is not yet standardised, limiting the opportunity to use data to drive improvement (Oxtoby and Mossop, 2016).

2. The skills regarded as crucial for successful QI in human healthcare are less cultivated in veterinary healthcare than in the NHS (Ballantyne, 2016) and this skills gap would need to be addressed.

3. While improvement in human healthcare is undoubtedly helped by top-down elements, it also requires engagement, skills, and confidence building 'from below' (Hocking et al., 2020b). This might include training, dispersed leadership, client engagement, communities of practice, and networks. These bottom up capacities are not yet formed (at this early stage) in the veterinary sector (Hocking et al., 2020a, 2020c)

Because of these contextual differences, simply transferring lessons wholesale from human healthcare might be unwise. There is a compelling argument that learning how to take QI forward in animal healthcare would need to be based in large measure on evidence collected from that sector. The research presented here intended to begin to address this evidence need. It aimed to address three overarching research questions:

1. What is the veterinary profession ${ }^{4}$ currently undertaking in their workplace to improve quality?

2. What shapes, or could shape, the veterinary professions motivations for being engaged and involved with QI?

3. What RCVS Knowledge and other stakeholders ${ }^{5}$ can do to overcome the barriers, and support the enablers for the veterinary profession, to engage with QI in practice?

METHODS \& MATERIALS

The methodology was designed to allow the research team to engage with a wide range of stakeholders, within the available resources. In summary, the mixed methods used included:

- a review of QI documents from the sector

- 18 semi-structured interviews with key stakeholders

- a survey of 471 members of the veterinary profession

\footnotetext{
${ }^{3}$ This will be referred to as the RCVS Code of Professional Conduct throughout the remainder of this article.

${ }^{4}$ For the purpose of this research, the veterinary profession includes veterinary surgeons, veterinary nurses and veterinary managers.

${ }^{5}$ By other stakeholders, the research team mean any organisation involved in the veterinary sector, such as universities and other educational institutions, individual veterinary practices and team members, professional veterinary organisations, the Veterinary Client Mediation Service, CPD providers and Practice Management System (PMS) providers, among others.
} 
- two focus groups with 14 PSS assessors

- a national summit attended by 50 policymakers and influencers from the veterinary profession

RCVS Knowledge provided support to the researchers, who had no prior experience of working in the veterinary industry, to assist in identifying relevant contacts or groups of contacts, however, it was important to RCVS Knowledge and RAND Europe to minimise the risk of bias with this approach. Mitigation strategies to prevent bias included:

- Carrying out focus groups with the PSS assessors who were familiar with many and varied practices, with a mandate to assess and assure the standards of clinical governance (among other standards). Their remit made them well-placed to understand the current landscape of $\mathrm{QI}$ in veterinary practices.

- Interviews up to an hour long were conducted by the researchers. Interviewees were a random selection $^{6}$ of 10 members of the profession using the databases of Members of the RCVS and Registered Veterinary Nurses held and maintained by the RCVS. All registered veterinary surgeons and veterinary nurses in the databases were included in the selection and allocated a unique number. Numbers were then randomly selected, and those individuals were invited to an interview.

- Inviting summit attendees through delegation by the leading veterinary organisations and policy makers who represent the breadth of the profession.

- Widely promoting the survey which was open to all those working in a veterinary practice setting in the UK.

All research participants were assured that the information that they provided would be used by the research team alone (RAND Europe), to analyse and report on the findings, and was not directly attributed to named participants. The intention of having an external organisation undertake the research (rather than this being done by RCVS Knowledge), was to mitigate the risk that participants might give biased views if they felt that their responses were available directly to an organisation who might be seen as too closely linked to their regulator.

\section{Orientation Document Review}

To help the research team orientate their work within existing knowledge and research they conducted a short document review of QI-related documents from RCVS, RCVS Knowledge, academic literature, large practice groups and professional bodies. This was carried out at the start of the research (January to February 2019). To identify relevant academic literature, RCVS Knowledge Library and Information Services conducted a literature search using keywords related to Ql:, the research team searched for keywords in the title/abstracts, including 'quality improvement', 'clinical governance', 'improvement' and 'clinical audit'. Articles not in English, books, podcasts, and descriptions of events/workshops without information on results were excluded. This led to nine articles identified as relevant and information extracted. In addition to this, RCVS Knowledge made available a list of 36 grey literature documents it identified as being relevant to the research (the full list of the 45 reviewed articles is in the supplementary material appendix 1 ). This included QI strategy documents and QI reports from RCVS Knowledge, large practice groups and RCVS webpages with QI information, such as the RCVS Code of Professional Conduct, among others. Each document was reviewed, and information from this has been incorporated throughout the article.

In addition to the documents sent by RCVS Knowledge, five key systematic reviews covering QI in human healthcare were included (see supplementary material appendix 2). The purpose of this was to explore where progress made within the veterinary sector by RCVS, RCVS Knowledge and others sits within the evidence base of human healthcare.

\footnotetext{
${ }^{6}$ While these were randomly selected, the researchers ensured that the individuals represented a broad profile of the profession including those who treat small animals; farm animals; equine; PSS-accredited practice; non-PSS-accredited practice; general practice; hospital; those from corporate or independent practices; veterinary surgeons, nurses; and practice managers.
} 


\section{Key Stakeholder Semi-Structured Interviews}

Eighteen semi-structured interviews were conducted with key stakeholders during March to May 2019 by telephone. The stakeholders, numbers, aims of the interviews and the references used throughout this article are shown in TABLE 1. The interviews were numbered sequentially in the order they were conducted in.

TABLE 1: THE NUMBER OF STAKEHOLDER INTERVIEWS, THE AIM OF INTERVIEWING EACH AND THE CODE USED TO REFERENCE INTERVIEW DATA THROUGHOUT THE REPORT

\begin{tabular}{|c|c|c|c|}
\hline STAKEHOLDER & $\begin{array}{c}\text { NUMBER } \\
\text { INTERVIEWED }\end{array}$ & AIM OF THE INTERVIEW & CODE \\
\hline Animal charity & 1 & $\begin{array}{l}\text { To understand the current QI initiatives in place } \\
\text { within the charity, the barriers and enablers } \\
\text { faced by animal charities and how QI can be } \\
\text { taken forward in the sector. }\end{array}$ & $\begin{array}{l}\text { INTX } \\
\text { charity }\end{array}$ \\
\hline Animal owner & 2 & $\begin{array}{l}\text { To provide perspectives on where animal } \\
\text { owners think improvements can be made in the } \\
\text { veterinary sector. }\end{array}$ & $\begin{array}{l}\text { INTX } \\
\text { owner }\end{array}$ \\
\hline $\begin{array}{l}\text { Members of the } \\
\text { profession }\end{array}$ & 10 & $\begin{array}{l}\text { To understand the current status of QI across } \\
\text { the veterinary sector, the motivations for } \\
\text { professionals to engage with QI and the } \\
\text { enablers and barriers they face, and how } \\
\text { professionals would like QI to be taken forward } \\
\text { in the veterinary sector. }\end{array}$ & $\begin{array}{c}\text { INTX } \\
\text { profession }\end{array}$ \\
\hline
\end{tabular}

\begin{tabular}{llll}
\hline $\begin{array}{c}\text { Large practice groups' } \\
\begin{array}{c}\text { Clinical Governance } \\
\text { leads }\end{array}\end{array}$ & $\begin{array}{c}\text { To understand the motivations and constraints } \\
\text { regarding QI for those in practice. }\end{array}$ & INTX LPG \\
\hline $\begin{array}{c}\text { To gain an understanding of the context of QI in } \\
\text { member }\end{array}$ & 1 & $\begin{array}{c}\text { the veterinary sector, the hopes for this project } \\
\text { and the role of the QIAB in QI now and in the } \\
\text { future. }\end{array}$ & INTX QIAB \\
\hline $\begin{array}{c}\text { Representatives from } \\
\text { organisations who deal } \\
\text { with veterinary clients' } \\
\text { complaints }\end{array}$ & 2 & $\begin{array}{c}\text { To cover the background of QI in the veterinary } \\
\text { sector and explore where animal owners think } \\
\text { improvements can be made in the sector. }\end{array}$ & INTX \\
\hline
\end{tabular}

The interviews were analysed using Nvivo7; 'nodes' were created for each interview question and the transcripts were coded within this template.

\footnotetext{
${ }^{7}$ See: https://www.qsrinternational.com/nvivo-qualitative-data-analysis-software/home
} 


\section{Survey of the Veterinary Profession}

The research team worked closely with RCVS Knowledge to design a national survey open to all members of the veterinary profession. Through this we explored how professionals working in the veterinary sector (including veterinary surgeons, veterinary nurses, and practice managers, as well as students and researchers/academics) thought about and use QI in their routine work. The survey questions covered: preferred QI terminology; actual and desired time spent on QI activities; use of RCVS Knowledge QI tools; QI training; impact of QI on their practice and veterinary care more widely; barriers and challenges in engaging with Ql; who is responsible for driving Ql; what support is needed to be involved in Ql; and awareness, understanding and views of the RCVS Code of Professional Conduct, and the PSS. Those respondents who did not agree to the consent questions were removed (14 participants) which left 471 responses which were analysed.

The survey was administered via the SmartSurvey platform and was disseminated by RCVS Knowledge through various channels to reach as many of the profession as possible. This included on the RCVS Knowledge website, social media channels, e-news and a blog post authored by a member of the research team. A press release was sent and was covered by: Veterinary Practice ; Vetpol; MRCVSonline; VNonline; Vet Community; VetNurse; and VetSurgeon ${ }^{8}$. It was promoted in RCVS e-news. In addition, several key veterinary organisations were directly invited to participate in the survey and share it within their professional networks (see supplementary material appendix 3 for a list of organisations). The survey was left open for a total of 6 weeks.

\section{Focus Groups with PSS Assessors}

Two focus groups with 14 PSS assessors were carried out in March 2019. The aim of the focus groups was to understand the motivations of the profession to become involved with QI (including applying and maintaining PSS accreditation) and to explore what RCVS and others could do to support QI going forward. Each focus group participant completed a consent form ahead of the focus group. Each focus group was recorded, transcribed and analysed in Nvivo alongside the interview data to identify themes from across the data collection methods. Data from the focus groups is referenced throughout this article using similar references as the interviews, either FG1 or FG2.

\section{RESULTS}

The research identified a wide range of evidence regarding the current status of $\mathrm{Q}$ I in the veterinary sector. Here we focused on what the research told us about how, and how far, QI might be taken forward in the veterinary profession. We reported on nine key sets of findings.

\section{ALTHOUGH THE VETERINARY PROFESSION IS AWARE OF QI THERE WAS VARIATION IN THE DEPTH OF THIS KNOWLEDGE}

QI and its related activities were understood by the survey participants in general, but with variations in how deep this knowledge was (Figure 1 and Figure 2). It was reported by one interviewee that awareness had increased during the previous decade due to there being a greater focus on it from RCVS and other bodies, particularly large group practices (INT9 profession). The introduction of QI activities has increased recently since the push made by RCVS Knowledge. For example CVS adopted a strategic approach after attending Skills Day 2017: Quality Improvement in Veterinary Practice, an event held by RCVS Knowledge (CVS Group PLC, 2018).

\footnotetext{
8 Vetpol, MRCVSonline; VNonline; Vet Community; VetNurse; and VetSurgeon are online news forums for the veterinary profession.
} 
Those who have a QI aspect within their role may be more likely to be aware of the types of activities that are used and of the resources available to support this (INT9 profession, INT10 profession, INT13 profession).

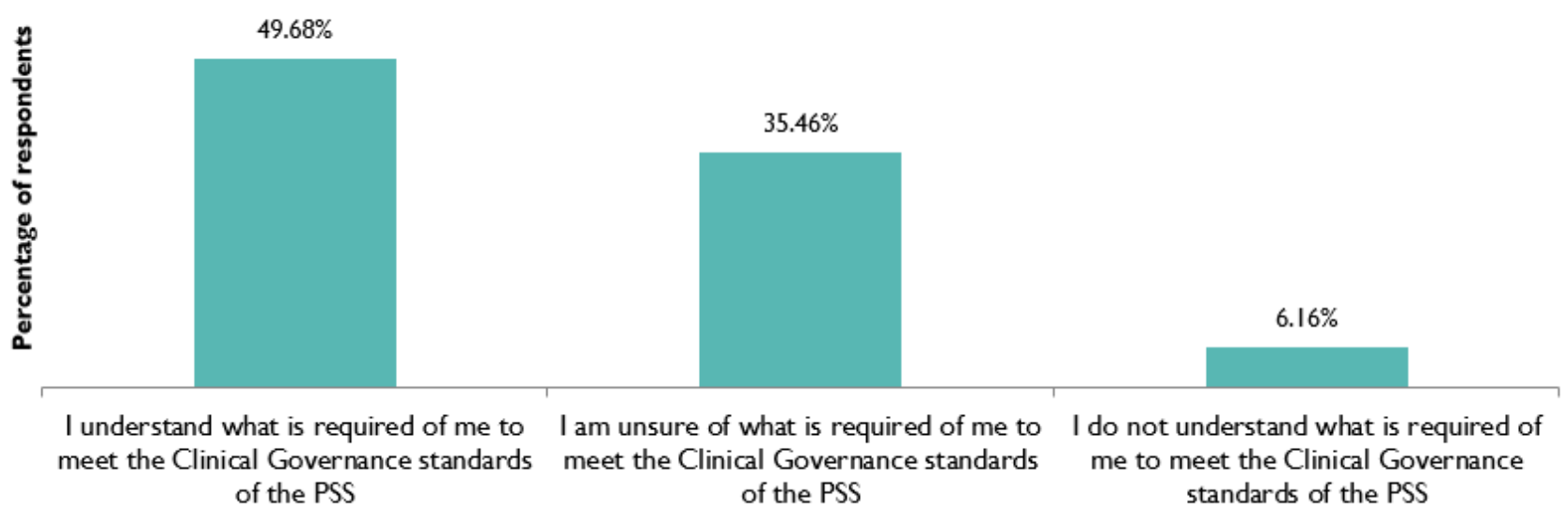

\section{FIGURE 1:}

SURVEY RESPONSES TO THE QUESTION: WHICH OF THE FOLLOWING STATEMENTS IS MOST APPLICABLE TO YOU AND YOUR PRACTICE ABOUT THE CLINICAL GOVERNANCE STANDARDS SET OUT IN THE PRACTICE STANDARDS SCHEME? ${ }^{9}$

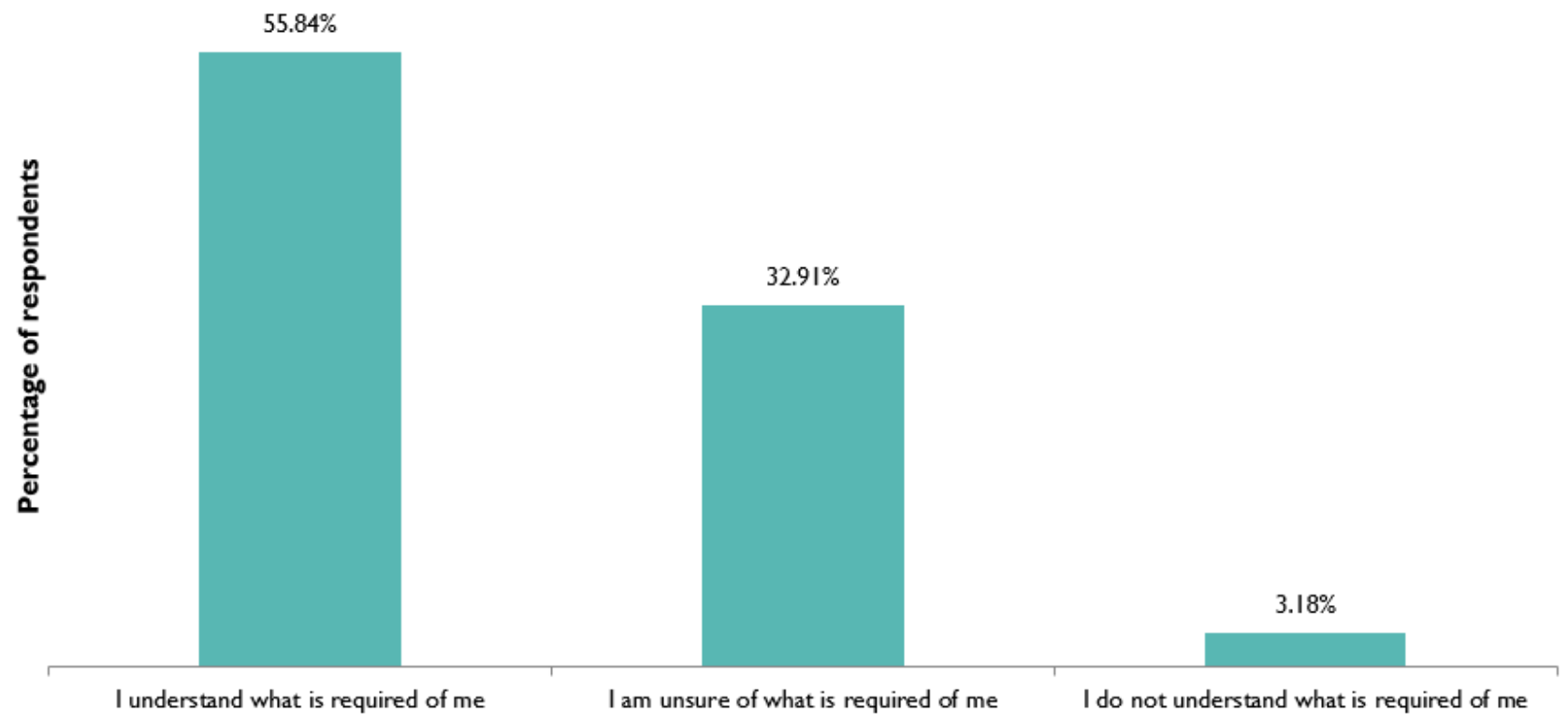

FIGURE 2:

SURVEY RESPONSES TO THE QUESTION: WHICH OF THE FOLLOWING STATEMENTS IS MOST APPLICABLE TO YOU ABOUT THE CLINICAL GOVERNANCE STANDARDS OF THE RCVS CODE OF PROFESSIONAL CONDUCT?

${ }^{9}$ These numbers do not add up to $100 \%$ as three individuals $(0.64 \%)$ did not complete this question and $8.07 \%$ (38 people) reported that they were not aware of the Clinical Governance standards of the PSS. 


\section{THE VETERINARY PROFESSION VIEWS QI AS A BENEFIT TO PRACTICE AND TO PATIENT CARE}

Almost all individuals consulted in the survey felt as though QI would improve the care they provided in their own practice $(95.97 \%)$ and across the UK $(98.09 \%)$. There is very little resistance to the idea of QI (see Figure 3 and Figure 4).

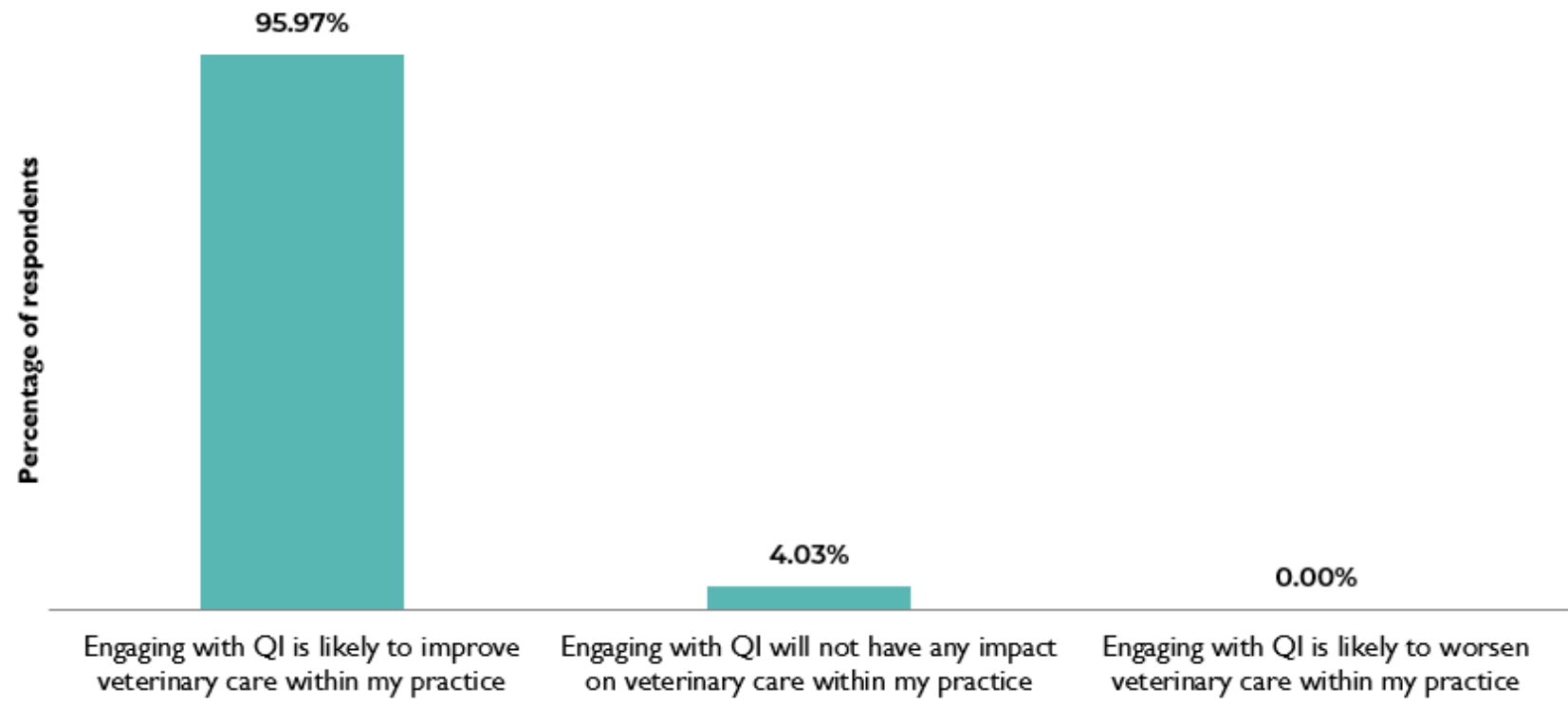

FIGURE 3:

SURVEY RESPONSES TO THE QUESTION: WHICH OF THE FOLLOWING STATEMENTS DO YOU AGREE WITH REGARDING THE IMPACT OF QUALITY IMPROVEMENT ON YOUR PRACTICE?

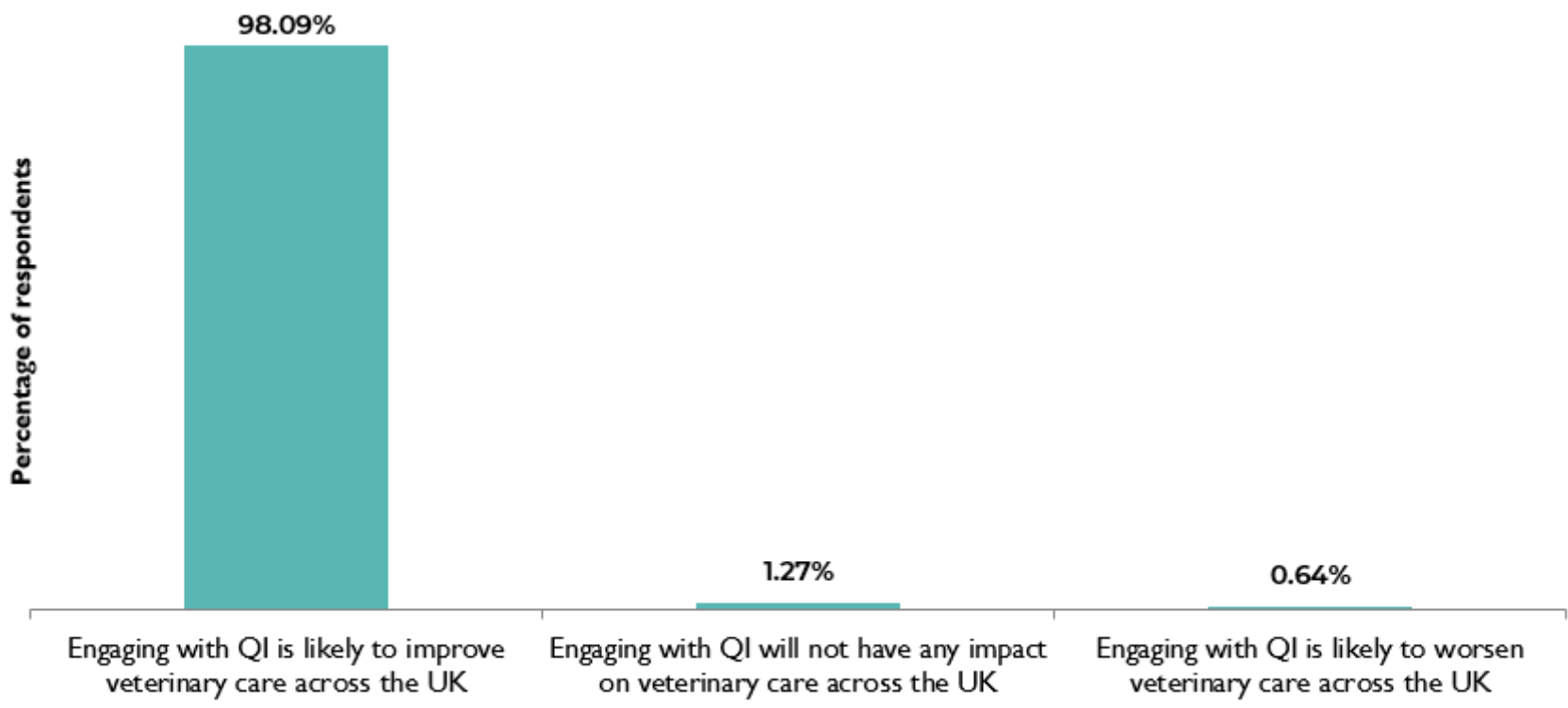

FIGURE 4:

SURVEY RESPONSES TO THE QUESTION: WHICH OF THE FOLLOWING STATEMENTS DO YOU AGREE WITH REGARDING THE IMPACT OF QUALITY IMPROVEMENT ON VETERINARY CARE ACROSS THE UK? 
Many interviewees discussed how they anticipated QI would allow them to provide the best care possible to animals and reduce adverse events (INT4 profession, INT7 profession, INT9 profession, INT11 profession, INT16 profession, INT18 profession).

'To stop critical events from happening, or try and prevent them as much as possible, and provide the best service that we could.' (INT16 profession)

'QI means striving to improve our clinical skills and improve a client's journey through a veterinary practice.' (INT14 profession)

Interviewees also anticipated that QI might improve the working of veterinary teams (and not just individuals), for example by increasing job satisfaction (INT4 profession, INT10 profession, INT11 profession).

'QI is trying to make sure that you are doing the right things that you should be doing and not just for the patient but for the client and staff as well.' (INT11 profession)

Many interviewees also discussed the importance of seeing QI as a journey of constant improvement rather than a one-step change to a better way of working (INT1 QIAB, INT9 profession, INT11 profession), including helping to keep up with changes in medicine (INT9 profession).

'It [QI] is a cyclical process rather than a journey from A to B.' (INT11 profession)

3. VETERINARY PROFESSIONALS VIEW THE PSS AND THE RCVS CODE OF PROFESSIONAL CONDUCT AS BENEFICIAL TO ANIMAL CARE AND TO PRACTICES, ALTHOUGH ON THEIR OWN THERE WERE MIXED VIEWS ON THE EXTENT TO WHICH THEY WOULD ENTRENCH QI IN VETERINARY PRACTICE

Overall, the interviewees held positive views of the PSS and felt as though it benefits business and patient care, although there were some concerns that the PSS assessment does not necessarily lead to changes in practice. So, although the PSS was believed to be a route to introducing QI to those who are not familiar with it (INT6 LPG, INT11 profession), and advice from the PSS assessors during the assessment was helpful for practices in guiding their QI activities, (FG1, INT13 profession) it was believed that on its own it was insufficient to entrench $Q$ I in veterinary practice.

'The PSS scheme is a good start and is a good guide to get the main [QI] things in place.' (INT11 profession)

'It [the PSS] is a good framework for starting QI.' (INT6 LPG)

As with the PSS, the survey explored whether members of the profession felt as though the RCVS Code of Professional Conduct supported QI and whether more could be done with the RCVS Code of Professional Conduct to help support QI further. As Figure 5 shows, $45.01 \%$ of the respondents felt as though the RCVS Code of Professional Conduct supported practices in improving the care they provided and only $6.16 \%$ felt it did not. However, $39.07 \%$ were unsure as to whether the RCVS Code of Professional Conduct supported QI. 


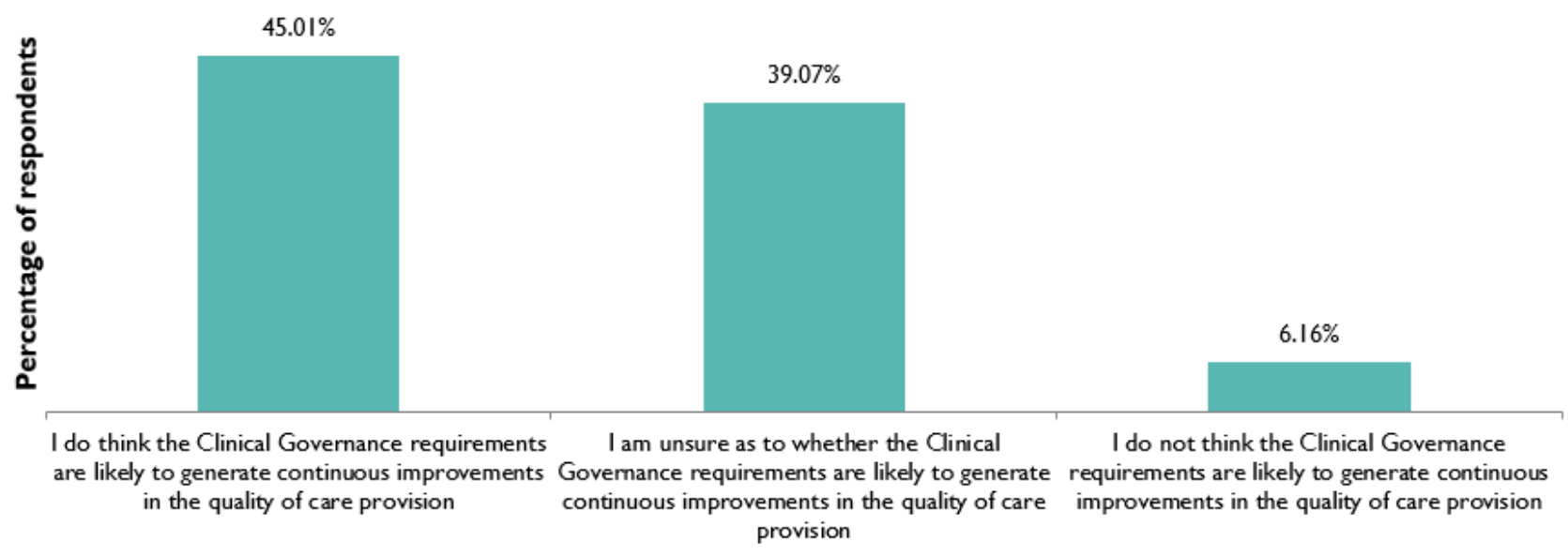

FIGURE 5:

SURVEY RESPONSES TO THE QUESTION: WHICH OF THE FOLLOWING STATEMENTS IS MOST APPLICABLE TO YOU ABOUT THE CLINICAL GOVERNANCE STANDARDS OF THE RCVS CODE OF PROFESSIONAL CONDUCT TO GENERATE CONTINUOUS IMPROVEMENT IN QUALITY OF CARE? ${ }^{10}$

4. ALTHOUGH, AS PART OF CLINICAL GOVERNANCE, QUALITY IMPROVEMENT ACTIVITIES ARE A PROFESSIONAL REQUIREMENT, MANY VETERINARY PROFESSIONALS ARE SPENDING LITTLE TO NO TIME ON IT

The survey investigated how much time respondents had spent on QI activities in the last year. As Figure 6 shows, almost $60 \%$ of respondents spent three days or less on QI over the previous 12 months. Of those, $11 \%$ reported that they had not spent any time on $\mathrm{Q}$ in that time frame. Analysis was conducted to explore the differences in time spent on QI across different demographics, including job role, animal species treated, practice type and age. The results were similar across these demographics, although those aged 65 and over appeared to spend more than 10 days on QI (67\% of this age group spent more than 10 days). The next closest to this was those aged 55-64 in which 29\% spent more than 10 days, which may reflect that those in more senior positions are able to dedicate more time to QI. For age in general, the trend appears to be that time spent on QI increases with age (Figure 7). Other demographics did not show significant differences in the survey. In addition, all interviewees could speak of at least one QI activity that was used in their practice.

${ }^{10}$ These numbers do not add up to $100 \%$ as three individuals (0.64\%) did not complete this question and $9.13 \%$ reported that they were unaware of the Clinical Governance section of the RCVS Code of Professional Conduct. 


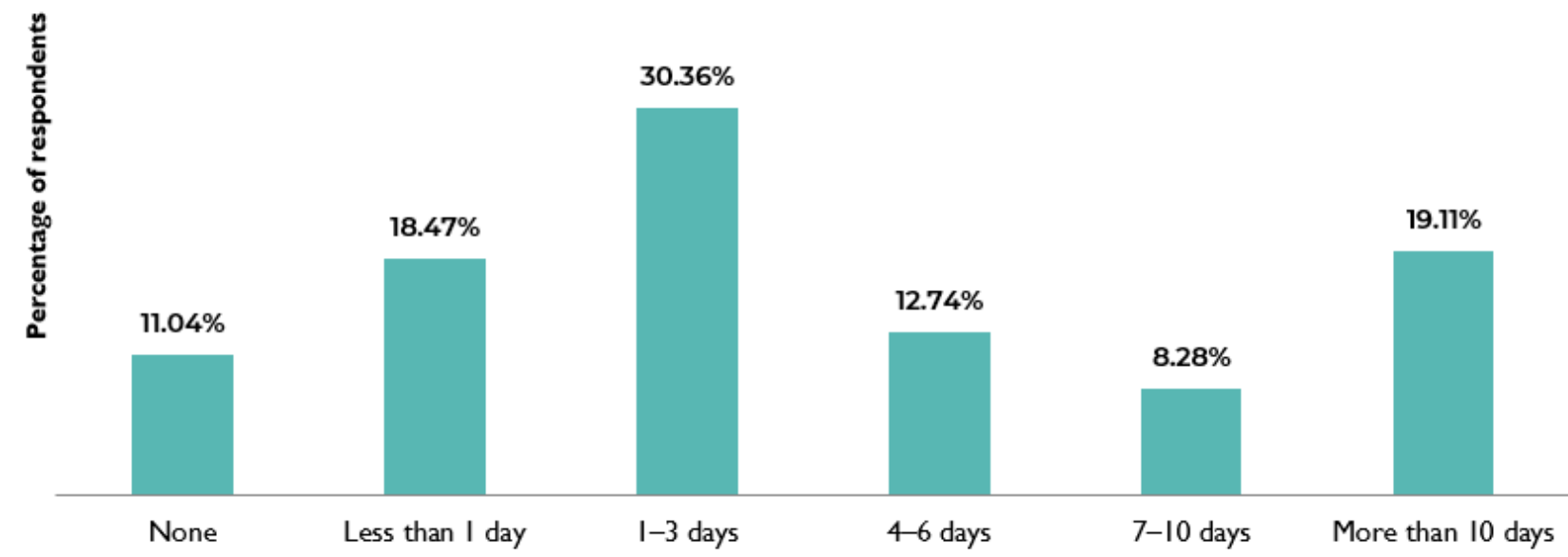

\section{FIGURE 6:}

SURVEY RESPONSES TO THE QUESTION: IN THE PAST 12 MONTHS, APPROXIMATELY HOW MUCH TIME IN TOTAL HAVE YOU SPENT ON QUALITY IMPROVEMENT ACTIVITIES?

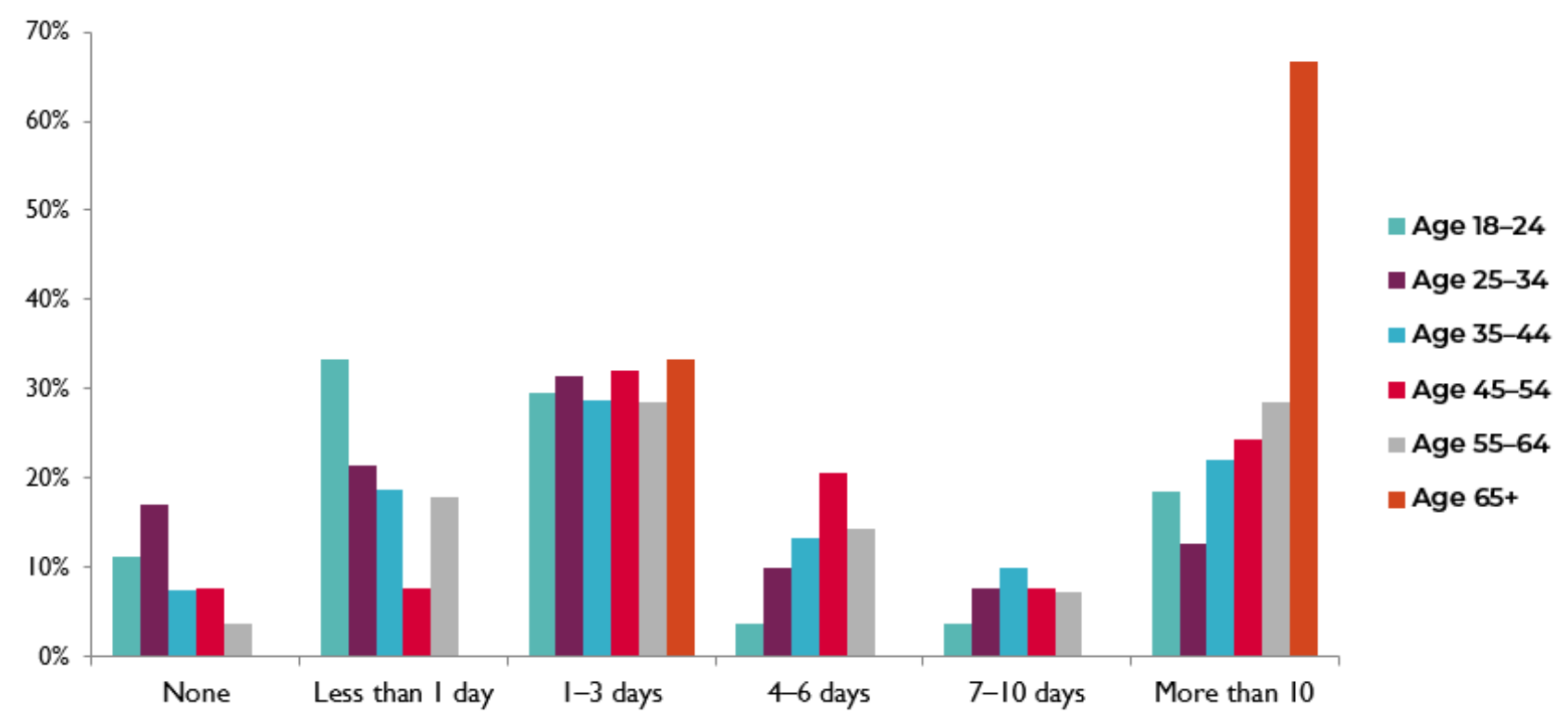

FIGURE 7:

SURVEY RESPONSES BY AGE TO THE QUESTION: IN THE PAST 12 MONTHS, APPROXIMATELY HOW MUCH TIME IN TOTAL HAVE YOU SPENT ON QUALITY IMPROVEMENT ACTIVITIES? ${ }^{11}$

\section{A RANGE OF QI ACTIVITIES ARE USED IN PRACTICE AND THESE ARE OFTEN DEVELOPED IN-HOUSE}

The survey explored which RCVS Knowledge QI tools were used by the survey participants over the past 6 months which is when they were launched. In this short time, around one-third of respondents reported

\footnotetext{
${ }^{11}$ Two participants selected the option 'prefer not to say' when asked for their age and these results are not included in this graph. There were 27 people in the 18-24 group, 182 people in the 25-34 group, 150 people in the 34-44 group, 78 people in the 45-54 group, and 29 people in the 55-64 group. The large percentage of those aged 65+ spending more than 10 days on QI is due to the small sample size (only three participants were in this age group).
} 
having used at least one, with $40 \%$ of respondents who had not used these resources indicating they would like to over the next 12 months. Only 10\% reported that they had not used any of the tools and did not intend to do so in the future. Of the responders who had used the RCVS Knowledge tools, around one-third had used checklists (34\%) and clinical audits (30\%). Very few respondents reported they had used benchmarking (8\%) and $6 \%$ of respondents had used other QI tools. When asked what 'other' tools were used, responses included both formal QI tools and more generic approaches to improving quality:

- QI tools developed in-house, including by large practice groups

- Continuing Professional Development

- information from colleagues

- wider literature

- social media

- similar tools to those offered by RCVS Knowledge but from other sources

6. THERE ARE MANY RESOURCES AVAILABLE TO SUPPORT PRACTICES IN GETTING STARTED WITH QI, AND CREATING DEDICATED QI LEADS CAN HELP EMBED IMPROVEMENT ACTIVITIES IN PRACTICE

Throughout the interviews and review of Ql-related documents, the research team identified multiple resources offered to practices to support QI activities. These largely fell into one of two categories:

- resources to get started with QI

- creating QI leads within practices

Interestingly, these were all offered by either RCVS Knowledge or developed in-house by large practice groups. The research team did not identify any information on this type of support offered by smaller practice groups. ${ }^{12}$

The support provided by large practice groups to implement QI seemed to be more common in practices that have been recently acquired. The types of resources offered are fairly similar to those offered by RCVS Knowledge in that they provide veterinary professionals with an understanding of what $\mathrm{Q}$ I is and provide resources to implement QI in practice.

One of the QI leads interviewed outlined initiatives in place in their practices (INT6 LPG). This includes creating terms of reference and agenda templates to guide QI-related meetings; QI training to educate professionals on what QI is and how to get started with it; and writing guidance on conducting QI activities, such as significant event audits. This interviewee reported that these resources help veterinary professionals to feel more at ease in getting involved with QI and allow them to feel more comfortable in introducing QI to their work (INT6 LPG).

\section{OUR RESEARCH IDENTIFIED KEY FACTORS IN SUPPORTING AND CHALLENGING QI IMPLEMENTATION}

A range of barriers to engaging with QI were reported by survey respondents and are shown in Figure 8. As this shows, the two main barriers identified, with over $50 \%$ of respondents, are a lack of time (55\%) and difficulty getting others in the practice on board (55\%). ${ }^{13}$

\footnotetext{
12 It is important to note that the research team did not explicitly ask this question in the interviews or survey, so participants may not have thought to share information on this.

${ }^{13}$ This adds up to more than $100 \%$ as participants could select more than one barrier.
} 


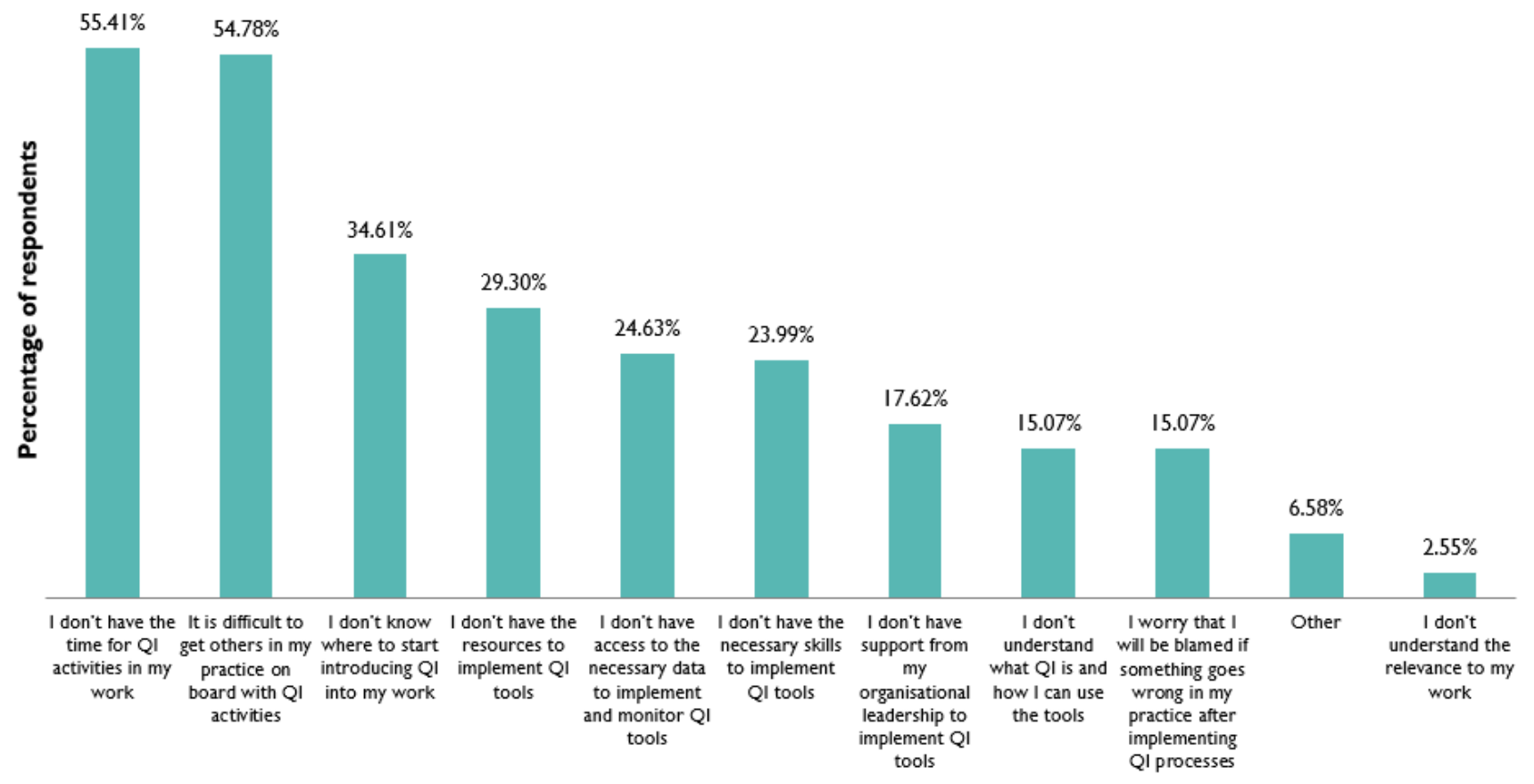

FIGURE 8:

SURVEY RESPONSES TO THE QUESTION: WHAT ARE THE MAIN BARRIERS AND CHALLENGES YOU FACE WHEN ENGAGING IN QUALITY IMPROVEMENT ACTIVITIES?

Interview and focus group participants were also asked to consider what would support and enable their future involvement in QI. Similar themes were identified from the survey.

The most frequently identified enablers and barriers from the survey, interviews and focus groups were:

- Lack of time was frequently highlighted as the biggest barrier when trying to engage with QI (INT1 QIAB, INT11 profession, INT12 profession, INT14 profession, INT16 profession).

- Support from colleagues and management was identified as an essential factor in implementing QI activities (INT10 profession, INT11 profession, INT5 animal owner, INT6 LPG).

- The availability of practical and QI-related resources and guidelines can influence the ease at which QI is implemented (INT11 profession, INT13 profession, INT6 LPG, INT8 LPG).

- Relevant and helpful training on QI was considered important, although challenges to making this widely available were acknowledged (INT6 LPG, INT9 profession).

- Variation in barriers and enablers were experienced by different types of practice (INT16 profession, INT18 profession, INT9 profession). For example, more specialised practices may find it easier to implement QI activities (INT7 profession, INT11 profession, INT12 profession, INT16 profession, INT6 LPG, FG1, INT4 charity). When looking at animal species treated, participants indicated that farm and equine vets may face additional barriers to QI (INT6 LPG, INT10 profession, INT13 profession, INT16 profession, INT7 profession, INT15 owner, FG2). Finally, smaller practice groups may face additional barriers and fewer enablers than large practice groups (INT1 QIAB, INT4 charity, INT6 LPG, INT8 LPG, INT7 profession, INT9 profession, INT11 profession, INT14 profession, INT17 profession, INT18 profession).

8. CLIENTS ARE GENERALLY NOT FAMILIAR WITH THE COMPLAINTS PROCEDURE, OR WITH QI ACTIVITIES THAT HAPPEN IN THE PRACTICES THEY VISIT

Throughout the interviews with members of the profession, those involved with client complaints and animal owners, it became clear that clients were generally not made aware of the Ql activities in the veterinary 
practices they visit and that these activities are more often seen as internal activities (INT3 complaints, INT4 charity, INT5 owner, INT7 profession, INT9 profession, INT10 profession, INT11 profession, INT14 profession, INT15 owner, INT16 profession, INT17 profession).

A variety of reasons were given as to why QI activities are not communicated to clients. Two interviewees commented that they had just never thought to share this type of information with their clients (INT7 profession, INT11 profession). There was also a concern that clients lack the knowledge needed to understand the care provision for their animal and the reasoning behind the decisions made for their care (INT1 QIAB, INT11 profession, INT17 profession).

\section{THERE ARE MIXED OPINIONS AS TO WHETHER CLIENTS SHOULD BE INVOLVED IN QI, ALTHOUGH FEEDBACK WAS THOUGHT TO PLAY AN IMPORTANT ROLE}

Only $8 \%$ (37 out of 471 ) of the survey respondents felt as though animal owners have a future role to play in QI. The interview with a member of the QIAB noted the asymmetries of knowledge that inevitably characterise this area (INT1 QIAB). However, this would be at odds with the premise of QI as was highlighted by definitions of QI given by some of the interviewees.

'Ql is trying to make sure that you are doing the right things that you should be doing and not just for the patient but for the client and staff as well.' (INT11 profession)

'QI means striving to improve our clinical skills and improve a client's journey through a veterinary practice.' (INT14 profession)

It may be that the knowledge held by a client on QI activities, such as audits, determines the extent of their involvement in QI activities (INT11 profession).

THE FUTURE OF QI: WHAT CAN VETERINARY STAKEHOLDERS DO TO SUPPORT QI GOING FORWARD?

The results from this research have so far shown the veterinary professions perceptions and understanding of QI, the current QI activities in use across the profession and the enablers and barriers to the profession engaging in QI. What is important to understand next is, based on these results, what can be done going forward, and by whom, to continue to support QI across the veterinary sector.

Based on our analysis, our summary conclusions regarding the role of wider stakeholders would be:

- RCVS could improve QI guidance and signposting to resources for practices, mandating certain aspects of QI (although this received mixed views from the research participants), ensuring there is a focus on improving team wellbeing and continuing to strengthen the QI aspects of the PSS.

- RCVS Knowledge could more widely promote the resources and guidance already available, as well as creating new resources and national data collection hubs to encourage improvement, campaign to demonstrate the importance and benefit of QI, and simplify QI language.

- Individual practices, including large and smaller practice groups, could appoint QI leads (which could involve those from both clinical and non-clinical roles) to help implement and sustain QI activities, introduce QI into Human Resources processes, introduce initiatives to encourage communication across the practice. The practices could create dedicated QI time as well as encourage uptake of the resources and data collection tools available through RCVS Knowledge. 
- Professional organisations could support RCVS Knowledge to develop and promote QI resources, as well as continuing to develop their own resources.

- Universities and educators could introduce a greater focus and unified approach to developing the skill-set required to deliver QI in education and as part of the curriculum, including modules on QI.

- CPD providers, which includes a range of organisations including individual practices and RCVS Knowledge, could incorporate QI into training and CPD to a greater extent.

- PMS providers could incorporate QI tools, such as using VeNom coding (VeNom Coding, 2020) and API functionality, into their systems.

- The Veterinary Client Mediation Service could support practices to learn from complaints and provide guidance on how to deal with complaints, including partnering with others to help to share lessons learned.

\section{DISCUSSION}

The future progress of QI in animal healthcare will take place and face a variety of challenges that were alluded to during the interviews, survey and focus groups, and which are apparent in wider discussions. QI is clearly not the sole answer to these new challenges but, in our view, should be seen to be part of a coherent response. Key challenges within the veterinary sector which will amplify the role of QI include:

- As animal owners become more informed and often have higher expectations, it becomes more important to have a formal system to show how quality issues are addressed.

- Similarly, there will be strong professional motivations to keep as narrow a gap as possible between the latest and best evidence and 'treatment as usual'.

- As veterinary practices grow in size, there are new opportunities to routinise QI, and more risks in not doing so.

- All of this will happen in the context of growing resource pressures reinforcing the need to identify wasteful practices that do not add value in the care of animals; QI is also concerned with stopping unnecessary procedures and reducing the time between procedures that add unnecessary costs or suffering to the animal.

In the light of these challenges, it is therefore perhaps not surprising that the survey results, interviews, focus groups and summit registered a strong appetite for QI.

Human healthcare is an obvious source of inspiration and ideas to support the embedding of QI in animal healthcare. However, there is a need to carefully tailor QI techniques to the circumstances of the improvement efforts.

QI in human healthcare is more mature than in the veterinary sector and this offers the opportunity to use lessons learned, ensuring that from the outset, implementation of $\mathrm{QI}$ in the veterinary sector supports both reliable data on the activities and clarity about impacts (Oxtoby \& Mossop, 2016).

Our survey also showed that support for the idea of QI is greater than the understanding of what Ql involves. Having engaged with the idea in principle, there is now a need to engage with it in practice.

In part, this should be achieved by the careful presentation of evidence. However, the evidence may not be enough to create meaning and to change behaviour. Therefore, without it becoming a marketing exercise without substance, by drawing on examples from elsewhere, evidence from the sector, thought leaders and so forth, QI should be branded and communicated, for example through narrative case examples of how and why QI has worked well. The view was expressed in the summit and in a focus group (FG1) that 'overselling' QI and 
giving it a 'cult status' would most likely lead to resistance. On the other hand, branding it as 'the way we do business around here' and as a helpful and practical way to provide better care within the available resources was seen to be a more likely route to success.

Professional identity is an important driver of behaviour (Godin et al., 2008). Medical knowledge is an important driver but so too is knowledge about tools to implement change, to understand the context and to measure results (Batalden \& Davidoff, 2007). In this sense, all those working in animal healthcare have two jobs: one to deliver healthcare and the other to improve it.

Training has a role to play in shaping professional identity. The research highlighted that Ql teaching (at university but also throughout veterinary careers) is patchy and many did not necessarily realise that the QI that they were doing was part of a more formal approach and so did not close the loop in monitoring these activities to ensure they are having the desired impact. Where QI is established as part of the expertise and knowledge, professionals need to do their job well and this informs the core curricula (rather than optional extras), new recruits to the veterinary workforce will more readily engage with QI activities.

However, throughout the research, the point was made to the research team repeatedly that if $\mathrm{QI}$ is to become the routine way of working, it needs to be made easy for those new to QI to engage, and with clear routes to participate. Supporting practices to have a package of QI activities and creating a community of practice whereby more experienced improvers can support new starters, could have a high impact.

The research unequivocally demonstrates the demand across the industry for RCVS Knowledge to support practice teams to embed full-cycle continuous QI for a structured and evidence-based approach to animal care. The organisation aims to lead a harmonised approach to QI that emphasises collaboration and shared learning to advance the delivery of quality care (RCVS Knowledge, 2017).

The research has shown that RCVS Knowledge's current approach provides a good foundation, and with fidelity to the techniques, and allowing time for veterinary specific evidence to accumulate, RCVS Knowledge can play the intermediary role for lessons to be learned and shared across the profession.

Whatever the merits of a social movement for improvement in the veterinary world, the view from the sector is that there should be evolution not revolution. The reasoning behind this is that there are already in place important parts of an improvement architecture, although they would have to be nudged and reshaped.

Mirroring findings from the human health sector (Ling et al., 2018; and Dixon-Woods et al. 2012), our survey for this research shows that time is a crucial barrier to engaging with QI. So too is the lack of clarity around how to easily engage with QI. Visible and predictable routes should be flagged along with the time commitment they involve. For example, different activities might be offered depending on how much time there is available in any one week.

The experience of improvers is that persistent packages, given enough time and addressing the whole flow of patient journey, trump one-off 'heroic' and narrowly-focused interventions. Creating a rhythm of learning alongside stability of practice allows lessons to be absorbed and improvements routinised. Doing good things well is better than doing perfect things sporadically and helps address the widespread concern that there is insufficient time for QI by making the time commitment more predictable and manageable.

The benefit of persistence over time is also relevant to the improvement architecture more widely ( $\varnothing$ vretveit, n.d.; and Ham et al., 2016). RCVS Knowledge has identified five key areas for action and focusing in this way should help achieve stability (RCVS Knowledge, 2017). The example of human healthcare improvement in Scotland is instructive in showing that it can take many years for an improvement approach to mature within a 
healthcare system (The Scottish Government, 2018). Providing a platform to support interpersonal engagement are reported by participants to be very powerful (Ling et al., 2018).

There is an important exception to the general benefit of consistency and continuity. From time to time there may be issues (perhaps identified through clinical audit) that identify a problem of quality but appear to be immune to merely persisting with existing Ql approaches. This is often because they are incompletely understood or because key stakeholders are mis-aligned. Under these circumstances, a one-off Improvement Lab designed to fully interrogate the problem and co-design solutions with key stakeholders has the potential to unlock chronic and deep-set problems (The Health Foundation, 2019). However, this would require additional resources, including the skills required to deliver such an approach.

The evidence presented here suggests that 'nudging the dial' to ramp up the role of QI activities is broadly supported, is believed to produce benefits for animals, and is believed to be achievable. We believe that we have presented here some steppingstones for delivering this change but we equally recognise that the engagement and enthusiasm of the veterinary profession will be key to future progress.

\section{CONFLICT OF INTEREST}

The authors declare no conflicts of interest.

This was funded in full by RCVS Knowledge.

Acknowledgements: Many thanks to all participants who contributed to this research.

REFERENCES

1. Practice facilitation handbook. Module 4: Approaches to quality improvement. Agency for Healthcare Research and Quality. [online] Available from: https://www.ahrq.gov/ncepcr/tools/pf-

handbook/mod4.html [Accessed 1/2/2021]

2. Ballantyne, H. (2016).Beyond the nursing care plan: an introduction to care bundles.Veterinary Nursing Journal. 31(2), 43-DOI: https://doi.org/10.1080/17415349.2015.1127787

3. Batalden, P. B. \& Davidoff, F. (2007). What is "quality improvement" and how can it transform healthcare? BMJ Quality \& Safety. 16(1), 2-3. DOI: http://dx.doi.org/10.1136/qshc.2006.022046

4. CVS Group publishes quality improvement and clinical governance report. CVS Group PIc. [online] Available from: https://www.cvsukltd.co.uk/cvs-group-publishes-quality-improvement-and-clinicalgovernance-report/ [Accessed 1/2/2021]

5. Dixon-Woods, M., McNicol, S. \& Martin, G. (2012). Ten challenges in improving quality in healthcare: lessons from the Health Foundation's programme evaluations and relevant literature. BMJ Quality \& Safety. 21(10), 876- DOI: http://dx.doi.org/10.1136/bmjqs-2011-000760

6. Godin, G., Bélanger-Gravel, A., Eccles, M. \& Grimshaw, J. (2008). Healthcare professionals' intentions and behaviours: A systematic review of studies based on social cognitive theories. Implementation Science. 3(36). DOI: https://doi.org/10.1186/1748-5908-3-36

7. Ham, C., Berwick, D, \& Dixon, J. (2016). Improving quality in the English NHS: A strategy for action. The King's Fund. [online] Available from: https://www.kingsfund.org.uk/sites/default/files/field/field publication file/Improving-qualityKings-Fund-February-2016.pdf [Accessed 04 May 2021] 
8. Hocking, L., Ling, T., Doorly, A. \& Gush, C. (2020a). Continuous quality improvement: a roadmap for the veterinary professions. RCVS Knowledge. [online] Available

from: https://knowledge.rcvs.org.uk/document-library/continuous-quality-improvement-a-roadmapfor-the-veterinary/ [Accessed 1/2/2021]

9. Hocking, L., Newbould, J., Parkinson, S., Stewart, K., Harshfield, A. \& Ling, T. (2020b). Strengthening the contribution of improvers to UK health and care? An evaluation of the Q Initiative 2016-2020. RAND. DOI: https://doi.org/10.7249/RRA166-1

10. Hocking, L., Picken, N. \& Ling, T. (2020c). Assessing the landscape and future actions for quality improvement in the veterinary sector. RCVS Knowledge. Available

from: https://knowledge.rcvs.org.uk/document-library/assessing-the-landscape-and-future-actionsfor-quality/ [Accessed 1/2/2021]

11. Institute of Medicine (US) Committee on Quality of Health Care in America. (2001). Crossing the quality chasm: A new health system for the 21st Century. National Academy Press. Available from: https://www.ncbi.nlm.nih.gov/books/NBK222274/ [Accessed 1/2/2021]

12. Institute of Medicine (US) Committee on Quality of Health Care in America. Kohn, L., Corrigan, J. \& Donaldson, M. (eds) (2000) To Err is Human: Building a Safer Health System. National Academies Press. Available from: https://www.ncbi.nlm.nih.gov/books/NBK225182/ [Accessed 1/2/2021]

13. T., Stewart, K., Garrod, B., Hocking, L., Newbould J. \& Gendronneau, C. (2018). Evaluation of the second phase of the $Q$ Initiative 2016-2020: Interim report. RAND.

DOI: https://doi.org/10.7249/RR2324

14. $\varnothing$ vretveit, J. Perspectives on context: How does context affect quality improvement? The Health Foundation. [online] Available from:https://www.health.org.uk/sites/default/files/PerspectivesOnContextOvretveitHowDoesContext AffectQualitylmprovement.pdf [Accessed 04 May 2021]

15. Oxtoby, C. \& Mossop, L. (2016). Checklists and clinical governance: learning from the NHS. In Practice. 38(8), 408-410. DOI: https://doi.org/10.1136/inp.i4561

16. Our commitment to QI (2017). RCVS Knowledge. [online] Available from: https://knowledge.rcvs.org.uk/quality-improvement/quality-improvement-project/ [Accessed $1 / 2 / 2021]$

17. Quality improvement. RCVS Knowledge. [online] Available from: https://knowledge.rcvs.org.uk/quality-improvement/ [Accessed 1/2/2021]

18. The $Q$ Improvement Lab. The Health Foundation. [online] Available from: https://q.health.org.uk/qimprovement-lab/ [Accessed 1/2/2021]

19. The Scottish Improvement Journey: a nationwide approach to improvement. (2018). The Scottish Government. [online] Available from: https://www.gov.scot/publications/scottish-improvementjourney-nationwide-approach-improvement-compiled-2016-17/ [Accessed 03/02/2021]

20. What are 'quality' and 'quality improvement'? The Health Foundation. [online] Available from: https://reader.health.org.uk/QualitylmprovementMadeSimple/what-are-quality-and-qualityimprovement [Accessed 1/2/2021]

21. VeNom: Veterinary nomenclature. VeNom Coding. [online] Available from: http://venomcoding.org/ [Accessed 1/2/2021] 


\section{Appendix 1-45 QI-related documents reviewed for the study:}

1. Oxtoby, C., Mossop, L., White, K. \& Ferguson, E. (2017). Safety culture: the Nottingham Veterinary Safety Culture Survey (NVSCS). Veterinary Record. 180(19), 472. DOI: https://doi.org/10.1136/vr.104215

2. Burford, J. \& Brennan, M. (2018). Investigating quality improvement methods in equine clinical practice. Find a PhD. [online] Available from: https://www.findaphd.com/phds/project/investigating-qualityimprovement-methods-in-equine-clinical-practice/?p96322 [Accessed 04 May 2021]

3. CVS Group PLC. (2018). Quality Improvement and Clinical Governance. [online] Available from: https://www.cvsukltd.co.uk/wp-content/uploads/2018/12/cvs-group-plc-qi-report-2018.pdf [Accessed 29 July 2019]

4. AniCura. (2018). Quality \& Sustainability Report 2018. [online] Available from: https://www.anicuragroup.com/globalassets/group/documents/quality/anicura---quality-andsustainability-report-2018.pdf [Accessed 29 July 2019]

5. RCVS. (2017). Strategic Plan 2017-2019. [online] Available from: https://www.rcvs.org.uk/how-wework/the-role-of-the-rcvs/strategic-plan/strategic-plan-2017-2019/ [Accessed 29 July 2019]

6. RCVS. Code of Professional Conduct for Veterinary Surgeons. [online] Available from: https://www.rcvs.org.uk/setting-standards/advice-and-guidance/code-of-professional-conduct-forveterinary-surgeons/ [Accessed 29 July 2019]

7. RCVS. Code of Professional Conduct for Veterinary Nurses. [online] Available from: https://www.rcvs.org.uk/setting-standards/advice-and-guidance/code-of-professional-conduct-forveterinary-nurses/ [Accessed 29 July 2019]

8. RCVS. About the Practice Standards Scheme. [online] Available from: https://www.rcvs.org.uk/settingstandards/practice-standards-scheme/about-the-practice-standards-scheme/ [Accessed 04 May 2021]

9. RCVS \& Work Psychology Group. (2018). Enhancing and supporting veterinary capabilities: A consultation on graduate and professional development phase outcomes. [online] Available from: https://www.rcvs.org.uk/news-and-views/publications/graduate-outcomes-consultation/ [Accessed 29 July 2019]

10. RCVS. (2017). RCVS Facts (2017). [online] Available from: https://www.rcvs.org.uk/news-andviews/publications/rcvs-facts-2017/?destination=\%2Fnews-and-views\%2Fpublications\%2F [Accessed 29 July 2019]

11. RCVS (2015) Awarding Organisation and Higher Education Institution Handbook. London: RCVS 12. RCVS. (2016). RCVS News (November 2016). [online] Available from: https://www.rcvs.org.uk/news-andviews/publications/rcvs-news-november-2016/?destination=\%2Fnews-and-

views\%2Fpublications\%2F\%3Fp\%3D3 [Accessed 04 May 2021]

13. RCVS. Certificate in Advanced Veterinary Practice (CertAVP). [online] Available

from: https://www.rcvs.org.uk/lifelong-learning/postgraduate-qualifications/certificate-in-advancedveterinary-practice-certavp/ [Accessed 29 July 2019]

14. RCVS. (2018). Proposed new framework for post-registration qualifications for veterinary nurses. [online] Available from: https://www.rcvs.org.uk/news-and-views/our-consultations/vn-post-registrationqualifications/ [Accessed 29 July 2019]

15. RCVS. (2019). Advanced Practitioner status. [online] Available from: https://www.rcvs.org.uk/lifelonglearning/professional-accreditation/advanced-practitioner-status/ [Accessed 29 July 2019]

16. RCVS. The role of the RCVS. [online] Available from: https://www.rcvs.org.uk/how-we-work/the-role-ofthe-rcvs/ [Accessed 04 May 2021]

17. RCVS. (2019). Advancement of the Professions Committee. [online] Available from: https://www.rcvs.org.uk/who-we-are/committees/advancement-of-the-professionscommittee/ [Accessed 04 May 2021] 
18. RCVS. Professional Development Phase (PDP). [online] Available from: https://www.rcvs.org.uk/lifelonglearning/professional-development-phase-pdp/ [Accessed 04 May 2021]

19. Vet Futures Project Board. (2015). Taking charge of our future: A vision for the veterinary profession for 2030. [online] Available from: https://www.vetfutures.org.uk/resource/vet-futures-report/ [Accessed 04 May 2021]

20. Vet Futures Action Group. (2016). Vet Futures Action Plan 2016-20. [online] Available from: https://www.vetfutures.org.uk/resource/vet-futures-action-plan-2016-20/ [Accessed 04 May 2021]

21. RCVS Knowledge. (2017). Is quality your cup of tea? [online] Available from: http://www.rcvskblog.org/isquality-your-cup-of-tea/ [Accessed 04 May 2021]

22. RCVS Knowledge. (2017). Building a learning culture: how quality improvement can help. [online] Available from: http://www.rcvskblog.org/building-a-learning-culture-how-quality-improvement-can-help/ [Accessed 04 May 2021]

23. Taylor, W. (2017). Quality Improvement and the NHS: Lessons for Vets. [online] Available from: http://www.rcvskblog.org/quality-improvement-and-the-nhs-lessons-for-vets/ [Accessed 04 May 2021]

24. Northway, L. (2018). Clinical audits - a veterinary nurse's perspective. [online] Available from: http://www.rcvskblog.org/clinical-audits-a-veterinary-nurses-perspective/ [Accessed 04 May 2021]

25. RCVS Knowledge. (2013). Strategic Plan 2017-2022. [online] Available from: https://knowledge.rcvs.org.uk/document-library/rcvs-knowledge-strategic-plan/ [Accessed 29 July 2019] 26. RCVS Knowledge. (2019). Quality Improvement. [online] Available from: https://knowledge.rcvs.org.uk/quality-improvement/ [Accessed 29 July 2019]

27. RCVS Knowledge. OnCOURSE. [online] Available from: https://oncourse.rcvsk.org/ [Accessed 29 July 2019] 28. RCVS Knowledge. VetAUDIT. [online] Available from: https://vetaudit.rcvsk.org/ [Accessed 13 July 2019] 29. RCVS Knowledge. (2017). Skills Day: Quality Improvement in Practice. [online] Available from: https://knowledge.rcvs.org.uk/quality-improvement/quality-improvement-project/skills-day-qualityimprovement-in-practice/ [Accessed 04 May 2021]

30. RCVS Knowledge. (2018). RCVS Knowledge at BSAVA Congress 2018. [online] Available from: https://knowledge.rcvs.org.uk/news-and-events/events/rcvs-knowledge-at-bsava-congress2018/ [Accessed 04 May 2021]

31. RCVS Knowledge. (2017). Quality Improvement in Veterinary Practice. [online] Available from: https://www.youtube.com/watch?app=desktop\&v=yx-epkDC3PQ\&feature=youtu.be [Accessed 04 May 2021]

32. RCVS Knowledge. (2018). Complication rates of neutering revealed in national audit. [online] Available from: https://knowledge.rcvs.org.uk/news-and-events/news/complication-rates-of-neutering-revealed-innational-audit/ [Accessed 04 May 2021]

33. App Advice. The VDS VetSafe system. [online] Available from: https://appadvice.com/app/the-veterinarydefence-society/1378187997 [Accessed 04 May 2021]

34. Viner, B. (2010). Success in Veterinary Practice: Maximising clinical outcomes and personal well-being. Wiley-Blackwell.

35. Oxtoby, C. \& Mossop, L. (2019). Blame and shame in the veterinary profession: barriers and facilitators to reporting significant events. Veterinary Record. 184(16), 501. DOI: https://doi.org/10.1136/vr.105137 36. RCVS. Ten common pitfalls and how to avoid them. Unpublished.

37. Mosedale, P. (2017). Learning from mistakes: the use of significant event audit in veterinary practice. Companion Animal. 22(3). DOI: https://doi.org/10.12968/coan.2017.22.3.140

38. Waine, K. (2017). Clinical audit experiences of veterinary surgeons undertaking farm animal work in the UK. Veterinary Evidence. 2(3). DOI: https://doi.org/10.18849/ve.v2i3.137

39. Turner, M. (2016). Mistakes, errors and foul-ups: practice-based evidence for evidence based practice. Veterinary Evidence. 1(4). DOI: https://doi.org/10.18849/ve.v1i4.69

40. Rose, N., Toews, L. \& Pang, D.S.J. (2016). A systematic review of clinical audit in companion animal veterinary medicine. BMC Veterinary Research. 12(40). DOI: https://doi.org/10.1186/s12917-016-0661-4

41. Viner, B. (2012). Clinical Governance. BSAVA manual of small animal practice management and development. 501-520. 
42. Oxtoby, C. \& Mossop, L. (2016). Checklists and clinical governance: learning from the NHS. In Practice. 38(8), 408-410. DOI: https://doi.org/10.1136/inp.i4561

43. Ballantyne, H. (2016). Beyond the nursing care plan: an introduction to care bundles. Veterinary Nursing Journal. 2016. 31(2),43-46. DOI: https://doi.org/10.1080/17415349.2015.1127787

44. Oxtoby, C. \& Mossop, L. (2016). Implementing checklists in practice. In Practice. 38(9):463-464.

DOI: https://doi.org/10.1136/inp.i4700

45. Clapham, L. (2015). Surgical safety: can a checklist really save lives? Veterinary Nursing Journal. 30(7):194198. DOI: https://doi.org/10.1080/17415349.2015.1042415

Appendix 2 - Five key systematic reviews covering QI in human healthcare reviewed for the study:

1. Amaratunga, T. \& Dobranowski, J. (2016). Systematic Review of the Application of Lean and Six Sigma Quality Improvement Methodologies in Radiology. Journal of the American College of Radiology. 13(19), 1088-1095. DOI: https://doi.org/10.1016/j.jacr.2016.02.033

2. Knudsen, V., Bering Laursen, H.V., Ehlers, L.H. \& Mainz, J. (2017). There is a need for improvement of quality improvement- A systematic review of the PDSA method in QI studies. International Journal for Quality in Health Care. 29(suppl_1), 45. DOI: https://doi.org/10.1093/intqhc/mzx125.72

3. Powell, A., Rushmar, R. \& Davies, H. (2009). A systematic narrative review of quality improvement models in health care. Quality Improvement Scotland. [online] Available

from: https://www.crd.york.ac.uk/CRDWeb/ShowRecord.asp?ID=32011000041\&ID=32011000041 [Acc essed 04 May 2021]

4. Janamian, T., Upham, S.J., Crossland, L. \& Jackson, C. (2016). Quality tools and resources to support organisational improvement integral to high-quality primary care: a systematic review of published and grey literature. Medical Journal of Australia. 204(57), S22-S28.

DOI: https://doi.org/10.5694/mja16.00113

5. Wells, S., Tamir, O., Gray, J., Naidoo, D., Bekhit, M. \& Goldmann, D. (2018). Are quality improvement collaboratives effective? A systematic review. BMJ Quality \& Safety. 27(3), 226-240.

DOI: http://dx.doi.org/10.1136/bmjqs-2017-006926

Appendix 3-Organisations directly invited to participate in the survey:

\begin{tabular}{|l|l|}
\hline $\begin{array}{l}\text { British Association of Veterinary Emergency and } \\
\text { Critical Care (BAVECC) }\end{array}$ & Companion Care/Vets4Pets \\
\hline $\begin{array}{l}\text { Veterinary Client Mediation Services (provided by } \\
\text { Nockolds Solicitors) }\end{array}$ & Veterinary Management Group (VMG) \\
\hline British Cattle Veterinary Association (BCVA) & CVS Group plc \\
\hline People's Dispensary for Sick Animals (PDSA) & The Veterinary Defence Society (VDS) \\
\hline Beaumont Sainsbury Animal Hospital & $\begin{array}{l}\text { Department for Environment, Food and Rural } \\
\text { Affairs (DEFRA) }\end{array}$ \\
\hline Queen Mother Hospital for Animals & VetPartners \\
\hline British Equine Veterinary Association (BEVA) & Dogs Trust \\
\hline Royal College of Veterinary Surgeons (RCVS) & Veterinary Schools Council \\
\hline Blue Cross & Veterinary Evidence \\
\hline RCVS Knowledge & VetCompass Animal Surveillance \\
\hline $\begin{array}{l}\text { British Small Animal Veterinary Association } \\
\text { (BSAVA) }\end{array}$ & $\begin{array}{l}\text { The Federation of Independent Veterinary } \\
\text { Practices (FIVP) }\end{array}$ \\
\hline $\begin{array}{l}\text { Royal Society for the Prevention of Cruelty to } \\
\text { Animals (RSPCA) }\end{array}$ & Davies Veterinary Specialists \\
\hline British Veterinary Association (BVA) & Goddard Veterinary Group \\
\hline
\end{tabular}




\begin{tabular}{|l|l|}
\hline $\begin{array}{l}\text { Small Animal Veterinary Surveillance Network } \\
\text { (SAVSNET) }\end{array}$ & VetLED \\
\hline British Veterinary Hospital Association (BVHA) & Independent Vetcare \\
\hline $\begin{array}{l}\text { The Society of Practising Veterinary Surgeons } \\
\text { (SPVS) }\end{array}$ & Vets Now Ltd \\
\hline British Veterinary Nursing Association (BVNA) & InFOCUS \\
\hline Stowe Veterinary Group & VN Futures \\
\hline $\begin{array}{l}\text { Centre for Evidence-based Veterinary Medicine } \\
\text { (CEVM) }\end{array}$ & Kernow Veterinary Group \\
\hline University of Liverpool & Wendover Heights Veterinary Centre \\
\hline City Road Vets & Linnaeus Group \\
\hline University of Nottingham & XLVets UK Ltd \\
\hline Newnham Court Equine Clinic & Medivet \\
\hline Damson House Vets & \\
\hline
\end{tabular}




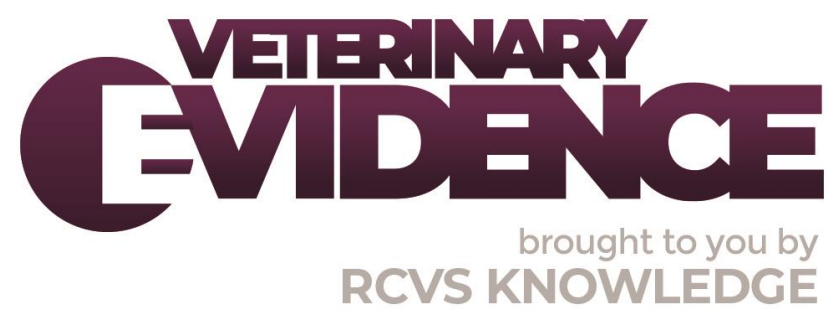

\section{Intellectual Property Rights}

Authors of Knowledge Summaries submitted to RCVS Knowledge for publication will retain copyright in their work, and will be required to grant RCVS Knowledge a non-exclusive license of the rights of copyright in the materials including but not limited to the right to publish, re-

publish, transmit, sell, distribute and otherwise use the materials in all languages and all media throughout the world, and to license or permit others to do so.

\section{Disclaimer}

Any opinions expressed in articles and other publication types published in Veterinary Evidence are the author's own and do not necessarily reflect the view of the RCVS Knowledge. Veterinary Evidence is a resource to help inform, and the content herein should not override the responsibility of the practitioner. Practitioners should also consider factors such as individual clinical expertise and judgement along with patient's circumstances and owners' values. Authors are responsible for the accuracy of the content. While the Editor and Publisher believe that all content herein are in accord with current recommendations and practice at the time of publication, they accept no legal responsibility for any errors or omissions, and make no warranty, express or implied, with respect to material contained within.

For further information please refer to our Terms of Use.

RCVS Knowledge is the independent charity associated with the Royal College of Veterinary Surgeons (RCVS). Our ambition is to become a global intermediary for evidence based veterinary knowledge by providing access to information that is of immediate value to practicing veterinary professionals and directly contributes to evidence based clinical decision-making.

https://www.veterinaryevidence.org/

RCVS Knowledge is a registered Charity No. 230886.

Registered as a Company limited by guarantee in England and Wales No. 598443.

Registered Office: Belgravia House, 62-64 Horseferry Road, London SW1P 2AF

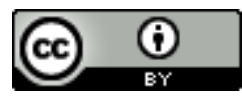

This work is licensed under a Creative Commons Attribution 4.0 International License. 